\title{
THE CONTRIBUTION OF GENES REQUIRED FOR ANAEROBIC RESPIRATION TO THE VIRULENCE OF SALMONELLA ENTERICA SEROVAR GALLINARUM FOR CHICKENS
}

\author{
J.B. Paiva'; R.A.C. Penha Filho' ${ }^{1}$; E.A. Pereira ${ }^{1}$; M.V.F. Lemos ${ }^{1}$; P.A. Barrow ${ }^{2}$ M.A. Lovell ${ }^{2}$; A. Berchieri Jr ${ }^{1 *}$
}

${ }^{1}$ Faculdade de Ciências Agrárias e Veterinárias, Universidade Estadual Paulista, Jaboticabal, SP, Brasil; ${ }^{2}$ School of Veterinary Medicine and Science, University of Nottingham, Sutton Bonington, Loughborough LE12 5RD, UK.

Submitted: January 20, 2009; Returned to authors for corrections: April 24, 2009; Approved: May 15, 2009.

\begin{abstract}
Salmonella enterica serovar Gallinarum (SG) is an intracellular pathogen of chickens. To survive, to invade and to multiply in the intestinal tract and intracellularly it depends on its ability to produce energy in anaerobic conditions. The fumarate reductase ( $\mathrm{fr} A A B C D)$, dimethyl sulfoxide (DMSO)-trimethylamine $N$-oxide (TMAO) reductase $(d m s A B C)$, and nitrate reductase (narGHIJ) operons in Salmonella Typhimurium (STM) encode enzymes involved in anaerobic respiration to the electron acceptors fumarate, DMSO, TMAO, and nitrate, respectively. They are regulated in response to nitrate and oxygen availability and changes in cell growth rate. In this study mortality rates of chickens challenged with mutants of Salmonella Gallinarum, which were defective in utilising anaerobic electron acceptors, were assessed in comparison to group of bird challenged with wild strain. The greatest degree of attenuation was observed with mutations affecting nitrate reductase (napA, narG) with additional attenuations induced by a mutation affecting fumarate reductase $(\operatorname{rrd} A)$ and a double mutant (dmsA tor $C$ ) affecting DMSO and TMAO reductase.
\end{abstract}

Key words: Salmonella Gallinarum, anaerobic genes, poultry, mutations.

\section{INTRODUCTION}

Fowl typhoid is caused by Salmonella enterica serovar Gallinarum (SG), a very severe disease of worldwide economic significance and where the mortality may reach up to $80 \%$. Disease is most severe where environmental conditions and management systems do not allow hygienic control measures to be introduced. Although a live vaccine (9R) is commercially available and has been used extensively it harbours undefined attenuations and retains a degree of virulence $(20,21,40)$. Although additional strains have been described which have more defined mutations $(4,6,7,23$, 49) none of these combine the high level of protection of the 9R strain, with has ability to stimulate high level of circulating specific antibody. There thus remains considerable scope for further exploration of the basis of virulence in this pathogen.

The mechanisms whereby bacterial pathogens generate energy during infection are poorly understood. The Enterobacteriaceae are facultative anaerobes with a modular

*Corresponding Author. Mailing address: Faculdade de Ciências Agrárias e Veterinárias, Universidade Estadual Paulista /FCAV-Unesp, Via Paulo Donato Castellane,s/n. 14884-900 Jaboticabal, São Paulo, Brazil.; Fone: 5516 32092662, fax: 55 16 32092859.; Ee-mail: berchier@ @cav.unesp.br 
respiratory system and which, in the absence of any externally supplied electron acceptors, may generate energy by substrate level phosphorylation. There is a strong hierarchy in the choice of electron acceptors, which are used, and with different bioenergetic efficiencies for the different donor/acceptor combinations.

Respiration in Escherichia coli and Salmonella enterica has been reviewed by Gennis \& Stewart (19) and Richardson (36). A variety of electron donors, including NADH, formate, lactate, glycerol-3-phosphate, succinate and pyruvate donate electrons to the quinone membrane pool which then pass the electrons to final acceptors including oxygen, nitrate, nitrite, DMSO, TMAO, fumarate and thiosulphate. At the first and final stages energy may be expended enabling protons to be translocated across the membrane creating an electrochemical tension from the proton gradient. The proton gradient generated by electron transport is used by the $\mathrm{F}_{0} \mathrm{~F}_{1}$ protontranslocating ATPase for ATP synthesis, flagella rotation, and nutrient uptake $(12,30)$. During fermentative growth, the bacterial $\mathrm{F}_{0} \mathrm{~F}_{1}$ proton-translocating ATPase hydrolyzes ATP to generate the proton gradient.

Despite the extensive understanding of bacterial electron transport and proton translocation, little is known about the relative contribution of the relevant proton-translocating and related enzymes to the growth and survival of pathogens in the host in either the gut or the intracellular environment. The contribution of NADH dehydrogenase I, cytochrome o- and d-oxidase and the $\mathrm{F}_{0} \mathrm{~F}_{1}$ ATPase to the virulence of serovars Typhimurium and Gallinarum in chickens and of serovar Dublin in mice have been determined through straight mutation exercises. Mutations crucially affecting enzyme activity, including nuoG, which codes for a key polypeptide of the NADH dehydrogenase I complex $(12,16)$, cyoA and cydA, which code for subunits of cytochrome $o$ and cytochrome $d$ oxidases, respectively (19), and atp $\mathrm{B}$ and $\operatorname{atp} \mathrm{H}$, which code for polypeptides of the $F_{0}$ and $F_{1}$ components, respectively, of the $\mathrm{F}_{0} \mathrm{~F}_{1}$ proton-translocating ATPase (24) were all found to contribute to virulence to different degrees. These studies indicated that different proton translocating proteins contributed to the virulence of $S$. enterica serovars, considering different pathotypes and host specificities in different ways. Mutations in $a t p B$ or atpH were attenuating in $S$. Typhimurium (ubiquitous), S. Dublin (mammalian specific causing typhoid in mice and severe disease in cattle) and SG (avian specific causing typhoid in chickens) while mutations in nuoG (NADH oxidoreductase) and $c y d \mathrm{~A}$ and $c y o \mathrm{~A}$ (cytochrome o and d oxidase respectively) were attenuating in $S$. Gallinarum they were less attenuating in Typhimurium and Dublin infections in mice (46).

The proton translocating enzymes above all use oxygen as electron acceptor. No information is currently available on the contribution of electron acceptors other than oxygen to virulence in Salmonella. Given that for most of these serovars infection is by the faecal oral route and the intestinal colonisation is an important initial phase of infection, even for those typhoid serovars that do not colonise the intestine extensively, it seems likely that metabolism and energy generation/respiration under conditions of reduced oxygen tension will be important at some stage of the infection process. In addition the work of Turner et al., (46) indicated that mutations in $c y o A$ were less attenuating than those in cydA indicating that growth at lower oxygen tension may be significant since cytochrome $\mathrm{d}$ is generally expressed at lower oxygen tensions (17). We therefore decided to assess the contribution of nitrate, fumarate, DMSO and TMAO to the virulence of SG in chickens.

\section{MATERIAL AND METHODS}

\section{Bacterial strain and culture media}

Salmonella Gallinarum strain 9 produces typical systemic fowl typhoid with high mortality $(34,42)$. For ease of enumeration spontaneous nalidixic acid-resistant $(25 \mu \mathrm{g} / \mathrm{mL})$ mutant derivates of this strain were used. This has been found previously not to affect their virulence (43). The mutants were constructed from Salmonella Typhimurium F98 $\mathrm{Nal}^{\mathrm{r}}$ strain. The DNA homology was such as to permit use the same inactivated serovar Typhimurium sequences in 
Paiva, J.B. et al.

serovar Gallinarum. The construction of the mutants, conjugation and transduction followed Sambrook \& Russel (39) and Turner et al. (46).

Unless otherwise stated, broth cultures consisted of $10 \mathrm{~mL} \mathrm{LB}$ broth (Invitrogen) incubated for $24 \mathrm{~h} / 37^{\circ} \mathrm{C}$ in a shaking incubator $(100 \mathrm{rpm})$. The broth culture contained approximately $1 \times 10^{8}$ (S. Gallinarum) and $1.2 \times 10^{9}(S$. Typhimurium) CFU/mL.

\section{Mutant construction}

Mutants were constructed in an identical way to the proton translocating-deficient mutants described previously (46). In brief, four primers were designed for each gene to be mutated such that two fragments close to the 5' and 3' ends (Table 1) of the gene could be amplified leaving a central deletion in the amplified gene and incorporating KpnI or BamHI sites facilitating insertion of a kanamycin or spectinomycin cassette. Initial cloning was into pGEM T
Easy (Promega) and then into the suicide vector pJCB12 in E.coli S.17.1入 pir, which was used for conjugation into Salmonella Gallinarum $9 \mathrm{Nal}^{\mathrm{r}}$. Mutants were selected by resistance to kanamycin or streptomycin and ampicillin sensitivity and were checked for their Salmonella O-serotype by slide agglutination with antisera and for smoothness by absence of agglutination with acriflavin (0.001\%). The integrity of the constructs was checked by PCR using the same primers. For the $S$. Gallinarum narZ and narG mutants an additional primer was used for the PCR derived from the deleted part of the gene (primer 5).

Transduction. Mutants of Salmonella Gallinarum with double deletions were obtained by transduction using bacteriophage P22 following standard protocols (5, 39). Transductants were plated on LB agar containing spectinomycin or kanamycin and after incubation at $37 \mathrm{C} / 24 \mathrm{~h}$ were again checked by PCR.

Table 1. Primers used for mutant construction.

\section{DmsA}

Primer 1:cgtctagaatgaaaactaagatcctga

Primer 3: tcatggggatcccatcttcaaacagcgtgacc

\section{TorC}

Primer 1: actctagaatgcgaaaactctggagagc

Primer 3: ggattgggtaccctgttctgaagtgaaagtc

\section{NarG}

Primer 1: cgtctagatgaactgcaccggttcttgta

Primer 3: attggcggtacctttcttataacgecggtta

Primer 5: taccatttcaccgttgcttgtt

\section{NarZ}

Primer 1: aatctagatcaaccacggcgtcaactg

Primer 3: tgtcatggtaccgaagatgagaaaattcgc

Primer 5: tttgatattctcgactgg

\section{NapA}

Primer 1:cgtctagaagctttatgaaagctaacgc

Primer 3: acaacaggatccgagctgggcttctatctg

\section{FrdA}

Primer 1: cgtctagaacctttcaagccgatcttgc

Primer 3: accatgggatccgaactggtggtgtttggt
Primer 2: aagatgggatcccatgaacgtgtcaaagtgc

Primer 4: actctagactgaacgaggttcgtatgtg

Primer 2: aagcagggtacccaatccetttatggcagtcg

Primer 4: catctagattcattgtgttctccettat

Primer 2: aagaaaggtaccgccaatcagcgaaagata

Primer 4: cgtctagatatgggtcggtttcggcgtaat

Primer 2: atcttcggtaccatgacagataacgtgttc

Primer 4: gctctagagaatgttcataatccgctcct

Primer 2: cagctcggatcctgttgttagagcggaaac

Primer 4: gatctagacggcatcgaagaacggcatat

Primer 2:cagttcggatcccatggttgtcatcaacca

Primer 4: gctctagattcaccgccgtaaacacgttt 


\section{Virulence assays}

Mortality rates were assessed by oral inoculation of fiveday-old brown commercial layers. This variety of chicken was chosen because it is susceptible to the clinical fowl typhoid $(10,18)$. Groups of 30 birds were challenged with $0.5 \mathrm{~mL}$ of either an undiluted culture contained $10^{8} \mathrm{CFU} / \mathrm{mL}$ or diluted at $10^{-2}$ to contained $10^{6} \mathrm{CFU} / \mathrm{mL}$. Mortality was recorded over a period of 30 days. Mortality in groups of birds inoculated with mutants of SG were compared to mortality in group inoculated with wild strain of SG using Chi-Square test $(\mathrm{p}<0.05)(22)$.

\section{RESULTS}

A $\mathrm{Km}^{\mathrm{r}}$ insertion cassette was made in genes $\operatorname{tor} \mathrm{C}, \operatorname{nar} \mathrm{G}$, and narZ and a $\mathrm{Spc}^{\mathrm{r}}$ insertion cassette was made in genes napA, frdA, dms A. The effects of the virulence of the SG mutants in the brown variety of layers are present in tables 2 and 3. Mortality shown in Table 2 did not differ among groups of birds inoculated with the SG mutant strains than that provoked by the wild strain of SG $\left(\chi^{2}, \mathrm{p}>0.05\right)$, except to $\mathrm{SG} \Delta f r d \mathrm{~A}$ that at lower dose provoked less mortality than the wild strain of SG $\left(\chi^{2}, p<0.05\right)$. The mortality was higher in groups inoculated with diluted cultures of $\mathrm{SG} \Delta \mathrm{d} m s \mathrm{~A}$ strain compared with the diluted culture of wild SG strain $\left(\chi^{2}\right.$, $\mathrm{p}<0.05$ ). Table 3 presents the results related to the remaining mutants. Both doses produced less mortality in birds inoculated with SG $\Delta n a r G$ and SG $\Delta$ napA strains in comparison with the wild SG strain $\left(\chi^{2}, \mathrm{p}<0.05\right)$. The difference was significant only to the higher dose to SG $\Delta$ narG $\Delta$ napA $\left(\chi^{2}, \mathrm{p}<0.05\right)$ and the lower dose to $\Delta$ tor $\mathrm{C} \Delta d m s \mathrm{~A}\left(\chi^{2}, \mathrm{p}<0.05\right)$.

Table 2. Mortality of 5-day-old brown commercial layers due to experimental Salmonella Gallinarum strains being defective in any gene related to anaerobic respiration.

\begin{tabular}{|c|c|c|c|c|c|c|c|c|c|c|c|c|c|c|c|c|c|c|c|c|c|c|c|c|c|c|}
\hline \multirow{2}{*}{$\Delta$} & \multirow{2}{*}{ CFU/mL } & \multicolumn{25}{|c|}{ Cumulative mortality at any day post infection (dpi) } \\
\hline & & 5 & 6 & 7 & 8 & 9 & 10 & 11 & 12 & 13 & 15 & 17 & 19 & 20 & 21 & 22 & 23 & 24 & 25 & 26 & 27 & 28 & 29 & 30 & Total\# & $\%$ \\
\hline \multirow{2}{*}{$d m s \mathrm{~A}$} & $10^{8}$ & 12 & 22 & 27 & & 28 & 29 & & & 30 & & & & & & & & & & & & & & & $30 \mathrm{a}$ & 100 \\
\hline & $10^{6}$ & & 2 & 3 & & & & 4 & & 6 & & 7 & 11 & 12 & & 14 & 21 & 23 & 25 & & & & 28 & & $28 \mathrm{c}$ & 93.33 \\
\hline \multirow{2}{*}{$\operatorname{tor} \mathrm{C}$} & $10^{8}$ & 7 & 22 & & 25 & 26 & 27 & & 28 & & 29 & & 30 & & & & & & & & & & & & $30 a$ & 100 \\
\hline & $10^{6}$ & 1 & & 2 & 4 & & & & & 5 & 6 & & & & 10 & & 12 & 14 & & 15 & 17 & 20 & & 21 & $21 \mathrm{~b}$ & 70 \\
\hline \multirow[t]{2}{*}{ narZ } & $10^{8}$ & & 3 & 13 & 24 & & 25 & & & & & & & & & & & 26 & & & & & & & $26 a$ & 86.67 \\
\hline & $10^{6}$ & & 1 & 8 & & 13 & 14 & 15 & & & & & & & & & & & & 17 & & & & & $17 \mathrm{ab}$ & 56.67 \\
\hline \multirow[t]{2}{*}{$f r d \mathrm{~A}$} & $10^{8}$ & & 5 & 12 & 16 & 18 & & 19 & 21 & 22 & & 23 & 25 & 26 & 27 & 28 & & & & & & & & & $28 \mathrm{a}$ & 93.33 \\
\hline & $10^{6}$ & & & 4 & 9 & 10 & & & & & & & & & & & & & & & 11 & & & & $11 \mathrm{a}$ & 36.67 \\
\hline \multirow[t]{2}{*}{ None* } & $10^{8}$ & 9 & 21 & 25 & & & & 26 & & & & & & & & & & & & & & & & & $26 \mathrm{a}$ & 96.30 \\
\hline & $10^{6}$ & 5 & 6 & 9 & 10 & 11 & & & & & 12 & & & 13 & 14 & & 23 & & & & & & 18 & 20 & $20 \mathrm{~b}$ & 64.52 \\
\hline
\end{tabular}

* Group of birds infected with the original strain of SGNal ${ }^{\mathrm{r}}$; \# Different letters to the same dilution between mutant and wild strains are significant by Chi-Square test $(\mathrm{p}<0.05)$.

\section{DISCUSSION AND CONCLUSION}

Fowl typhoid is a systemic disease of chickens caused by $\mathrm{SG}$, an intracellular anaerobic facultative parasite. The disease is very severe and during its course the bacterium persists intracellularly. The virulence factors are responsible for the development and evolution of the illness (47). In addition, the bacterium also utilized other resources to survive intracellularly. To respire anaerobically Salmonella produces enzymatic complexes according to the available substrate into the host cell. Sometimes, under certain circumstances, the enzymatic complexes could inhibit the action of each other. According to Mahan et al. (29), there is direct association among expression of genes related to 
Paiva, J.B. et al.

anaerobic process and expression of genes related to invasion process. This would provide to the bacterium better favorable energetic way to survive and to growth. The virulence of STM decreases in a strain with altered genes encoding enzymes of the metabolic pathway of respiratory process (31). Therefore, genes responsible for the respiratory enzymes production could be regulated in the same process that encodes invasiveness $(13,41)$.

Table 3. Mortality of 5-day-old brown commercial layer due to experimental Salmonella Gallinarum strains being defective in any gene related to anaerobic respiration.

\begin{tabular}{|c|c|c|c|c|c|c|c|c|c|c|c|c|c|c|c|c|c|c|c|c|c|c|c|c|}
\hline \multirow{2}{*}{$\Delta$} & \multirow{2}{*}{ CFU/mL } & \multicolumn{23}{|c|}{ Cumulative mortality at any day post infection (dpi) } \\
\hline & & 4 & 5 & 6 & 7 & 8 & 9 & 10 & 11 & 12 & 13 & 14 & 15 & 16 & 18 & 19 & 20 & 21 & 22 & 23 & 24 & 25 & Total\# & $\%$ \\
\hline \multirow[t]{2}{*}{ narG } & $10^{8}$ & & & & 1 & 3 & 5 & 10 & 11 & 14 & 15 & 20 & & 21 & & & 22 & & 23 & 24 & & & $24 \mathrm{~b}$ & 80 \\
\hline & $10^{6}$ & & & 1 & 3 & & 5 & 7 & & 8 & & & 9 & & & & & & & & & & $9 \mathrm{a}$ & 30 \\
\hline \multirow[t]{2}{*}{$\operatorname{napA}$} & $10^{8}$ & & 1 & 9 & 15 & 16 & 19 & 20 & 21 & & & & & & & 22 & & & & & & & $22 \mathrm{~b}$ & 73.33 \\
\hline & $10^{6}$ & & 1 & 2 & & & & 3 & & & & 4 & & & & & & & & 5 & & & $5 \mathrm{a}$ & 16.67 \\
\hline \multirow[t]{2}{*}{ torC/dms A } & $10^{8}$ & 1 & 4 & 7 & 12 & 17 & 22 & & 23 & & & & & & & & 24 & 25 & & & & & $25 \mathrm{a}$ & 83.33 \\
\hline & $10^{6}$ & & 2 & 4 & 9 & & & & & & & & & & & & & & & & & & $9 \mathrm{a}$ & 30 \\
\hline \multirow[t]{2}{*}{ narG/napA } & $10^{8}$ & & 2 & 5 & 11 & 17 & 20 & 21 & & & & & & 22 & & & & & 23 & & & 24 & $24 \mathrm{~b}$ & 80 \\
\hline & $10^{6}$ & 1 & & 4 & 8 & & 11 & & & & 12 & & & & & & & & & 13 & 14 & & $14 \mathrm{~b}$ & 46.67 \\
\hline \multirow[t]{2}{*}{ narZ/napA } & $10^{8}$ & & 3 & 11 & 19 & 22 & & 25 & 26 & & & & 27 & & & & & 28 & 29 & & & & $29 \mathrm{a}$ & 96.67 \\
\hline & $10^{6}$ & & 1 & 5 & 8 & 10 & 14 & & & & & & & & & & & & & & 15 & & $15 \mathrm{~b}$ & 50 \\
\hline \multirow[t]{2}{*}{ None* } & $10^{8}$ & 2 & 4 & 10 & 18 & 21 & 24 & 27 & 28 & 29 & & & & & 29 & 30 & & & & & & & $30 \mathrm{a}$ & 100 \\
\hline & $10^{6}$ & & 4 & 12 & 15 & 17 & & 18 & & & & & & & & & & & & & & & $18 \mathrm{~b}$ & 60 \\
\hline
\end{tabular}

*Group of birds infected with the original strain of SGNal ${ }^{\mathrm{r}}$; Different letters to the same dilution between mutant and wild strains are significant by Chi-Square test $(\mathrm{p}<0.05)$.

In the present work mutants of SG containing defective genes related to anaerobic respiration were prepared. These mutants were inoculated orally in 5-day-old chickens susceptible to clinical fowl typhoid. The results are reported in tables 2 and 3 . The mortality in groups of birds inoculated with SG $\Delta n a r \mathrm{G}, \mathrm{SG} \Delta f r d \mathrm{~A}, \mathrm{SG} \Delta n a p \mathrm{~A}, \mathrm{SG} \Delta t o r \mathrm{C} \Delta d m s \mathrm{~A}$ a strain was lower in comparison with that inoculated with the wild SG strain $(\mathrm{p}<0.05 \%)$. Conversely, SG $\Delta d m s \mathrm{~A}$ provoked higher mortality in comparison to the wild strain ( $p$ $<0.05 \%)$.

When the defective mutant did not alter the course of the disease it is possible to speculate in two ways: the activity of the altered gene did not interfere in the enzyme performance or the enzyme, if inactivated, is not essential either because the microorganism may produce other enzyme with similar activity or the host cell has several substrates available. According to Moreno-Vivían \& Ferguson (32) the enzymes may have distinct activity under different metabolic conditions. The assimilatory and dissimilatory vias could be connected to facilitate the rapid adaptation during the changing from aerobic to anaerobic ambient, increasing the chance of surviving in the host. Perhaps, for this reason, some mutants continued expressing the same profile even after the insertion of the defective gene.

Members of the Enterobacteriaceae express three different nitrate reductases $(3,71)$ encoded by narGHJI (Nitrate reductase A), narUZYWV (15) that appears to be expressed at low levels and a periplasmic reductase encoded by napFDAGHBC with NapA as the catalytic unit $(33,44)$. The mid-point potentials $\left(\mathrm{E}_{\mathrm{m}, 7}\right)$ of electron donor and acceptor couples to nitrate reductase have been determined. Thus $\mathrm{E}_{\mathrm{m}, 7}$ for $\mathrm{NO}_{3}{ }^{-} / \mathrm{NO}_{2}{ }^{-}$is $+433 \mathrm{mV}$ (45). This is likely to provide a crude estimation of the redox conditions at the site of multiplication within the macrophage, which is thought 
generally to be the acidified phagolysosome (1). Thus, in spleenic macrophages and Kupfer cells the redox conditions are quite high, which must reflect the conditions experienced by most bacterial pathogens that multiply in this site in the chicken, such as Mycobacterium avium. This may not be the case for other animals including mammals and this may represent a basis for determining the host specificity of different Salmonella enterica pathovars.

The mid-point potential for the other electron donor/acceptor couples involved are $+30 \mathrm{mV}$ fumarate/succinate $(45),+160 \mathrm{mV}$ for $\left(\mathrm{CH}_{3}\right)_{2} \mathrm{SO} /\left(\mathrm{CH}_{3}\right)_{2} \mathrm{~S}$ (48) and $+130 \mathrm{mV}$ for $\left(\mathrm{CH}_{3}\right)_{3} \mathrm{~N} /\left(\mathrm{CH}_{3}\right)_{3} \mathrm{NH}^{+}(3,25,26)$. These values are considerably lower than the value for nitrate/nitrite above or for oxygen $(+818 \mathrm{mV}, 45)$. This suggests that respiration within the intracellular environment of the macrophage, where cytochromes o- and d-oxidase and now nitrate reductase are actives and mutation of which attenuates virulence, occurs under redox conditions which are considerably more positive than the environments where fumarate, DMSO and TMAO or related compounds are likely to be active. This suggests that these may be active in the intestinal phase of the infection which, despite the fact that typhoid serovars such as SG colonise the gut poorly in the absence of clinical disease, do have an active early intestinal phase to systemic infection (38). The redox conditions are highly likely to be much more negative and further investigations to evaluate their role would be of value. Despite of these enzymes are not so efficient in regarding to catabolism like nitrate reductases, the lower mortality would be due the decrease in the production of essential substances. In Wolinella succiogenes fumarate reductase enzyme is implicated in generation of ATP (35), to create protons gradient through citoplasmatic membrane $(11,27)$. Also the fumarate would be the most important source of succinate in Bacterioides fragilis $(8,28)$ and finally, bacterium like E. coli requires succinate for succinyl-coA synthesis. Succinyl-coA is an essential cofactor in biosynthesis of metionine, diaminopimelic acid and lysine $(9,14)$.

According to the experimental model adopted when the challenge was done with diluted culture of the strain containing single mutation in $\operatorname{nar} \mathrm{G}$, frdA and nap $\mathrm{A}$ genes or double mutation in tor $\mathrm{C}$ and $d m s \mathrm{~A}$ the mortality was lower than that observed in control group. On another hand single deletion in narZ, $d m s \mathrm{~A}$ e tor $\mathrm{C}$ genes did not interfere in the relation between $\mathrm{SG}$ and the birds.

\section{ACKNOWLEDGEMENTS}

The authors would like to acknowledge the financial support from FAPESP and CNPq.

\section{REFERENCES}

1. Alpuche-Aranda, C.M.; Berthiaume, E.P.; Mock, B.; Swanson, J.A.; Miller, S.I. (1995). Spacious phagosome formation within mouse macrophages correlates with Salmonella serotype pathogenicity and host susceptibility. Infect. Immun. 63 (11), 4456-62.

2. Barret, E.L.; Kwan, H.S. (1985). Bacterial reduction of trimethylamine oxide. Апnu. Rev. Microbiol. 39, 131-149.

3. Barrow, P.A. (1990). Immunity to experimental fowl typhoid in chickens induced by a virulence plasmid-cured derivative of Salmonella gallinarum. Infect. Immun. 58 (7), 2283-2288.

4. Barrow, P.A.; Hassan, J.O.; Berchieri, A.Jr. (1990). Reduction in faecal excretion by chickens of Salmonella typhimurium by immunization with avirulent mutants of S. typhimurium. Epidemiol. Infect.104 (3), 413-426.

5. Barrow, P.A.; Lovell, M.A.; Old, D.C. (1992). In-vitro and in-vivo characteristics of TnphoA mutant strains of Salmonella serotype Gallinarum not invasive for tissue culture cells. J. Med. Microbiol. 36, 389-397.

6. Barrow, P.A.; Lovell, M.A.; Stocker, B.A.D. (2000). Protection against experimental fowl typhoid by parenteral admininstration of live SL5928, an $\operatorname{aroA}-\operatorname{serC}$ (aromatic dependent) mutant of a wild-type Salmonella Gallinarum strain made lysogenic for P22sie. Avian Pathol. 29 (5), 423-431.

7. Baughn, A.D.; Malany, H. (2002). A mitochondrial-like aconitase in the bacterium Bacteroides fragilis: implications for the evolution of the mitochondrial Krebs cycle. Proc. Natl. Acad. Sci. U S A. 99 (7) 46624667.

8. Baughn, A.D; Malamy, M.H. (2003). The essential role of fumarate reductase in haem-dependent growth stimulation of Bacteroides fragilis. Microbiol. 149 (6) 1551-1558.

9. Berchieri Jr, A.; Oliveira, G.H.; Pinheiro, L.A.P.; Barrow, P.A. (2000). Experimental Salmonella Gallinarum infection in light laying hens lines. Braz. J. Microbiol. 31 (1), 50-52.

10. Biel, S.; Simon, J.; Gross, R.; Ruiz, T.; Ruitenberg, M.; Kröger, A. (2002). Reconstitution of coupled fumarate respiration in liposomes by 
Paiva, J.B. et al.

incorporating the electron transport enzymes isolated from Wolinella succinogenes. Eur. J. Biochem. 269 (7), 1974-1983.

11. Bradbeer, C. (1993). The proton motive force drives the outermembrane transportation of cobalamin in Escherichia coli. J. Bacteriol. 175 (10), 3146-3150.

12. Buchmeier, N.A.; Heffron, F. (1989). Intracellular survival of wildtype Salmonella Typhimurium and macrophage-sensitive mutants in diverse populations of macrophages. Infect Immun..57, 1-7.

13. Clark, D.P. (1989). The fermentation pathways of Escherichia coli. FEMS Microbiol. Rev, 63 (3), 223-234.

14. Clegg, S.J.; Jia, W.; Cole, J.A. (2006). Role of the Escherichia coli nitrate transport protein, Nar $\mathrm{U}$, in survival during severe nutrient starvation and slow growth. Microbiology. 152 (2006), 2091-2100.

15. Falk-Krzesinski, H.J.; Wolfe, A.J. (1998). Genetic analysis of the nuo locus, which encodes the proton-translocating NADH dehydrogenase in Escherichia coli. J. Bacteriol. 180 (5), 1174-1184.

16. Fu, H.A.; Iuchi, S.; Lin, E.C.C. (1991). The requirement of ArcA and Rnr for peak expression of the cyd operon in Escherichia coli under microaerobic conditions. Mol. Gen. Genet. 226, 209-213.

17. Freitas, O.C.; Arroyave, W.; Alessi, A.C.; Fagliari, J.J.; Berchieri Jr, A. (2007). Infection of commercial laying hens with Salmonella Gallinarum: Clinical, anatomopathological and haematological studies. Braz. J. Poultry Sci. 9 (2), 133-141.

18. Gennis, R.B.; Stwart, V. (1996). Respiration. In: Neidhardt, F.C., Curtiss III R., Ingraham, J.L., Lin, E.C.C., Low K.B., Maganasik, B., Reznikoff, W.S. Riley, M., Schaechter, M., Umbarger, H.E. (eds). Escherichia coli and Salmonella: Cellular and molecular biology. American Society for Microbiology, Washington D.C., USA, p. 217 261.

19. Gordon, R.F.; Garside, J.S.; Tucker, J.F. (1959). A note on the use of living attenuated vaccines in the control of fowl typhoid. Vet. Rec. 71, 300-305.

20. Gordon, W.A.M.; Luke, D. (1959). A note on the use of the 9R fowl typhoid vaccine in poultry breeding flocks. Vet. Rec. 71, 926-927.

21. Greenwood, P.S.; Nikulin, M.S. (1996). In: Wiley, J. (ed). A Guide to Chi-Squared Testing. New York.

22. Griffin, H.G.; Barrow, P.A. (1993). Construction of an aroA mutant of Salmonella serotype Gallinarum: its effectiveness in immunization against experimental fowl typhoid. Vaccine. 11 (4), 457-462.

23. Harold, F.M.; Maloney, P.C. (1996). Energy transduction by ion currents. In: Neidhardt, F.C.; Curtiss III R.; Ingraham, J.L.; Lin, E.C.C.; Low K.B.; Maganasik, B.; Reznikoff, W.S.; Riley, M.; Schaechter, M.; Umbarger, H.E. (eds). Escherichia coli and Salmonella: cellular and molecular biology. American Society for Microbiology, Washington, D.C, USA, p. 283-306.

24. Kwan, H.S.; Barrett, E.L. (1983a). Purification and properties of trimethylamine oxide reductase from Salmonella typhimurium. J. Bacteriol. 155 (3), 1455-1458.
25. Kwan, H.S.; Barrett, E.L. (1983b). Roles for menaquinone and the two trimethylamine oxide (TMAO) reductases in TMAO respiration in Salmonella typhimurium: $\operatorname{Mud}\left(\mathrm{Ap}^{\mathrm{r}}\right.$ lac)insertion mutation in men and tor. J. Bacteriol. 155 (3), 1147-1155.

26. Lancaster, C.; Gross, R.; Haas, S.A.; Ritter, M.; Mantele, W.; Simon, J.; Kroger, A. (2000). Essential role of Glu C66 for menaquinol oxidation indicates transmembrane electrochemical potential generation by Wolinella succinogenes fumarate reductase. Proc. Natl. Acad. Sci.. 97 13051-13056.

27. Macy, J.; Probst, I.; Gottschalk, G. (1975). Evidence for cytochrome involvement in fumarate reduction and adenosine 5'-triphosphate synthesis by Bacteroides fragilis grown in the presence of hemin. $J$. Bacteriol. 123( 2), 436-442.

28. Mahan, M.J.; Slauch, J.M.; Mekalanos, J.J. (1993). Selection of bacterial virulence genes that are specifically induced in host tissues. Science. 259 (5095), 686-688.

29. Maloney, P.C.; Wilson, T.H. (1996). Ion-coupled transport and transporters. In: Neidhardt, F.C., Curtiss III, R., Ingraham, J.L., Lin, E.C.C., Low, K.B., Maganasik, B., Reznikoff, W.S., Riley, M., Schaechter, M., Umbarger, H.E. (eds). Escherichia coli and Salmonella: cellular and molecular biology. American Society for Microbiology, Washington, D.C., USA, p. 1130-1148.

30. Moor, M.A.; Portnoy, D.A. (1995). Identification of bacterial genes that contribute to survival and growth in an intracellular environment. Trends. Microbiol. 3 (3), 83-85.

31. Moreno-Vivían, C., Ferguson, S.J. (1998). Definition and distinction between assimilatory, dissimilatory and respiratory pathways. Mol. Microbiol. 29, 664-666.

32. Nilovangse, A; Brondijk, T.H; Overton, T.W.; Richardson, D.J.; Leach, E.R.; Cole, J.A. (2006). The NapF protein of the Escherichia coli periplasmic nitrate reductase system: demonstration of a cytoplasmic location and interaction with the catalytic subunit, NapA. Microbiology. 152 (11), 3227-3237.

33. Oliveira, G.H.; Fernandes, A.C.; Berchieri Jr.A. (2005). Experimental infection of laying hens with Salmonella enterica serovar Gallinarum. Braz. J. Microbiol. 36 (1), 51-56.

34. Reedy, C.A.; Peck, H.D. (1978). Electron transport phosphorylation coupled to fumarate reduction by $\mathrm{H} 2-$ and $\mathrm{Mg} 2+$ dependent adenosine triphosphatase activity in extracts of the rumen anaerobe Vibrio succinogenes. J. Bacteriol.. 134 (3), 982-991.

35. Richardson, D.J. (2000). Bacterial respiration: a flexible process for a changing environment. Microbiology, 146 (2000), 551-571.

36. Richardson, B.J.; Berks, B.C.; Russel, D.A.; Spiro, S.A.; Taylor, C.J. (2001). Functional, biochemical and genetic diversity of prokaryotic nitrate reductases. Cell. Mol. Life Sci. 58 (2), 165-178.

37. Rychlik, I.; Lovell, M.A.; Barrow, P.A. (1998). The presence of genes homologous to the $\mathrm{K} 88$ genes $\mathrm{faeH}$ and faeI on the virulence plasmid of Salmonella gallinarum. FEMS Microbiol. Lett. 159 (2), 255-260. 
38. Sambrook, J.; Russel, D.W. (2001). Molecular cloning. A laboratory manual. Cold Spring Harbor Laboratory Press.

39. Silva, E.N.; Snoeyenbos, G.H.; Weinack, O.M.; Smyser, C.F. (1981). Studies on the use of the $9 \mathrm{R}$ strain of Salmonella Gallinarum as a vaccine in chickens. Avian Dis. 25 (1), 38-52.

40. Singh, D.R.; Khullar, M.; Ganguly, N.K. (2000) Role of anaerobiosis in virulence of Salmonella Typhimurium. Mol. Cell. Biol. 215 (1), 39-46.

41. Smith, H.W. (1955). Observations on experimental fowl typhoid. $J$. Comp. Pathol. 65 (1), 37-54.

42. Smith, H.W.; Tucker, J.F. (1980). The virulence of Salmonella for chickens; their excretion by infected chickens. J. Hyg. 84 (3), 479-488.

43. Stewart, V.; Lu, Y.; Darwin, A.J. (2002). Periplasmic nitrate reductase (NapABC enzyme) supports anaerobic respiration by Escherichia coli K12. J. Bacteriol. 184 (5), 1314-1323.

44. Thauer, R.K.; Hungermann, K.; Decker, K. (1977). Energy conservation in chemotrophic anaerobic bacteria. Bact. Rev. 41 (1),
100-180.

45. Turner, A.K.; Zhang-Barber, L.; Wigley, P.; Muhammad, S.; Jones, M.A.; Lovell, M.A.; Hulme, S.; Barrow, P.A. (2003). Contribution of proton-translocating proteins to virulence of Salmonella enterica serovars Typhimurim, Gallinarum, and Dublin in chickens and mice. Infect. Immun. 71 (6), 3392-3401.

46. Van Immerseel, F.; Methner, U.; Rychlik, I.; Nagy, B.; Velge, P.; Martin, G.; Foster, N.; Ducatelle, R.; Barrow, P.A. (2005). Vaccination and early protection against non-host-specific Salmonella serotypes in poultry: exploitation of innate immunity and microbial activity. Epidemiol. Infect., 133, 959-978.

47. Wood, P.M. (1981). The redox potential for dimethylsulfoxide reduction to dimethylsulphide. FEBS Letts. 124 (1), 11-14.

48. Zhang-Barber, L.; Turner, A.K.; Dougan, G.; Barrow, P.A. (1998). Protection of chickens against experimental fowl typhoid using a nuoG mutant of Salmonella serotype Gallinarum. Vaccine. 16 (9), 899-903. 